\title{
Health-related quality of life and associated factors among cervical cancer patients at Tikur Anbessa specialized hospital, Addis Ababa, Ethiopia
}

\author{
Liya Teklu Araya ${ }^{1}$, Teferi Gedif Fenta ${ }^{1}$, Beate Sander ${ }^{2,3,4,5}$, Girma Tekle Gebremariam ${ }^{6}$ and
} Gebremedhin Beedemariam Gebretekle ${ }^{1 *}$

\begin{abstract}
Background: Cancer of the cervix is the most frequent cancer among women in Ethiopia. The disease burden and its treatment adversely affects patients' health-related quality of life (HRQOL). We aimed to investigate the HRQoL and its predictors among cervical cancer patients in Ethiopia.

Methods: A hospital-based cross-sectional study was conducted from January to June 2018 at the oncology unit of Tikur Anbessa Specialized Hospital, Addis Ababa, Ethiopia. A total of 404 cervical cancer patients were interviewed using validated Amharic version of the European Organization for Research and Treatment of Cancer module (EORTC QLQ-C30), cervical cancer module (EORTC QLQ-CX24), and Euro Quality of Life Group's 5-Domain Questionnaires 5-Levels (EQ-5D) questionnaires. ANOVA test was used to determine the effect of patients' characteristics on mean scores of the different domains of HRQOL and stepwise multivariable logistic regression was performed to identify predictors of HRQoL. Coefficients of level-specific utility values obtained from a hybrid regression model for the Ethiopian general population were used to compute utility.

Results: The mean age of patients was $52.1 \pm 10.4$ years and 379 (93.8\%) of the patients were receiving service at the outpatient clinic. About one-third (35\%) of patients were diagnosed with stage IV cervical cancer. Mean global health status/QoL, mean utility and visual analog scale scores were $48.3 \pm 23.77,0.77$ and $65.7 \pm 20.83$, respectively. Physical functioning ( $A O R=4.98,95 \% \mathrm{Cl}: 2.16-11.49)$, emotional functioning ( $A O R=5.25,95 \% \mathrm{Cl}: 2.26-12.17)$, pain ( $\mathrm{AOR}=5.79$, $95 \% \mathrm{Cl}: 2.30-14.57)$, and symptom experience (AOR $=4.58,95 \% \mathrm{Cl}: 1.95-10.79)$ were associated with patients' HRQoL.

Conclusions: Cervical cancer significantly affects patient's HRQOL and hence, efforts to improve HRQoL should be commenced especially in terms of physical and emotional functioning, pain, and symptom experience.
\end{abstract}

Keywords: Cervical cancer, EQ-5D, Ethiopia, Health-related quality of life, Utility

* Correspondence: gebremedhin.beedemariam@aau.edu.et

${ }^{1}$ Social and Administrative Pharmacy Unit, School of Pharmacy, College of Health Sciences, Addis Ababa University, Zambia Street, P.O. Box: 1176, Addis Ababa, Ethiopia

Full list of author information is available at the end of the article

\section{Introduction}

Cervical cancer is the fourth most common cancer worldwide that affecting women with estimated incidence and mortality of 56,9847 and 31,1365 , respectively, which accounts for $6.6 \%$ of all female cancers [1]. While cervical cancer survival rates are improving in developed nations, its burden in the low- and middle-

C The Author(s). 2020 Open Access This article is licensed under a Creative Commons Attribution 4.0 International License, which permits use, sharing, adaptation, distribution and reproduction in any medium or format, as long as you give appropriate credit to the original author(s) and the source, provide a link to the Creative Commons licence, and indicate if changes were made. The images or other third party material in this article are included in the article's Creative Commons licence, unless indicated otherwise in a credit line to the material. If material is not included in the article's Creative Commons licence and your intended use is not permitted by statutory regulation or exceeds the permitted use, you will need to obtain permission directly from the copyright holder. To view a copy of this licence, visit http://creativecommons.org/licenses/by/4.0/. The Creative Commons Public Domain Dedication waiver (http://creativecommons.org/publicdomain/zero/1.0/) applies to the data made available in this article, unless otherwise stated in a credit line to the data. 
income countries (LMICs) is high where nearly $90 \%$ of cervical cancer deaths are from these countries [1, 2]. The annual incidence of cervical cancer in the horn of Africa is 52,633 , which leads to high mortality and morbidity [1]. The high burden of cervical cancer in LMICs is largely because the majority of cases are detected in advanced stages which in turn was ascribed to the low screening rate as a result of lack of access to health care facilities [2].

Cervical cancer is the second leading cancer among women cancer in Ethiopia. According to 2018 reports, the estimated annual number of new cervical cancer cases were 6294 while the number of cervical cancer-related deaths were 4884 annually [3]. Despite the government effort to promote screening for early diagnosis of cervical cancer, patients were diagnosed at advanced stages, leading to long periods of illness, loss of productivity and premature deaths [1]. Further, there are few oncology centers and the treatment options are limited and costly. Ethiopia has only one radiotherapy center at Tikur Anbessa Specialized Hospital and that means all patients have to travel from different regions of the country to this hospital to get the radiotherapy service $[4,5]$. Therefore, cervical cancer is becoming an important health issue that affects the patient's HRQoL [6].

HRQoL is the subjective perception of the impact of disease and treatment on the health status of the patients that encompasses domains related to physical, functional, psychosocial or emotional functioning, that used to examine the impact of disease and its treatment on HRQoL $[7,8]$. It is a multidimensional and complex concept that reflects patients' experiences with the disease and treatment [9]. Both disease and its treatment burden are known to have an impact on the quality of life. So, the assessment of HRQoL in cervical cancer patients is important in order to design interventions for improving patients' outcomes.

Several generic and disease-specific tools have been developed for assessing HRQoL and its assessment has been made a routine practice in developed nations $[10,11]$. The European Organization for Research and Treatment of Cancer module (EORTC QLQ-C30), and cervical cancer module (EORTC QLQ-CX24) are among the diseasespecific tools that are most often used to evaluate HRQoL in cancer survivors $[12,13]$. Generic tools are also utilized in the economic evaluations of health interventions as they provide a multidimensional description of health, which generates quality-adjusted life-years [14]. The Euro QoL 5-Dimension questionnaire (EQ-5D) is also among the widely used generic instrument to evaluate HRQoL [15]. We aimed to evaluate the HRQoL and its associated factors in patients with cervical cancer in Ethiopia.

\section{Methods}

\section{Study design and participants}

A hospital-based cross-sectional study was conducted among cervical cancer patients who visited Tikur
Anbessa Specialized Hospital from January to June 2018. A total of 404 patients with cervical cancer were approached for the interview. Patients were considered eligible if they had a pathologically diagnosed cervical cancer, were 18 years or older, were able to understand and answer the questions, and were able to speak and communicate well in the local (Amharic) language. Patients were excluded from the interview if they were unwilling to participate, unable to understand questionnaires as decided by their physician as well as had a cognitive or mental problem.

\section{Instruments}

We selected generic and disease-specific instruments, which are commonly used to measure HRQoL of patients with cancer, and permission to use the instruments was obtained from the respective institutions. We used three different validated instruments: EQ-5D-5 L, EORTC QLQ-C30 and EORTC QLQ-CX24 module (supplementary file-1). Details of each tool and sub-domains are described below.

\section{EORTC-QLQ-C30}

The 30-items EORTC QLQ-C30 is psychometrically robust, cross-culturally accepted and most frequently used tool to assess HRQoL. It is grouped into 15 domains, including five functional subscales (physical functioning, role functioning, emotional functioning, cognitive functioning, and social functioning); three multi-item symptom subscales (fatigue, nausea/vomiting, and pain); global health status/QoL subscale; and six single items addressing various symptoms and perceived financial impact [12].

\section{EORTC-QLQ- CX24}

The 24-items EORTC QLQ-CX24 classified into three multi-item scales, eleven items with symptom experience domain, three items with body image domain, and four items with sexual/vaginal functioning domain. The other domains of the questionnaire are single-item scales, including lymphedema, peripheral neuropathy, menopausal symptom, sexual worry, sexual activity, and sexual enjoyment [13].

\section{$E Q-5 D$}

EQ-5D is a standardized measure of health status developed by the EuroQol Group in order to provide a simple, generic measure of health status for clinical and economic evaluations. It has five dimensions (mobility, self-care, usual activities, pain/discomfort, and anxiety/ depression) with a five-point scale ("Not at all" to "Extreme"). The visual analog scale (VAS) measures the patient's self-reported health on a $20 \mathrm{~cm}$ vertical scale, which ranges from 100 (best imaginable health state) to 0 (death or worst imaginable health state) [14-17]. 


\section{Data collection procedures}

Patients who fulfilled the eligibility criteria were enrolled consecutively during their visit to the oncology clinic and a face-to-face interview was carried out to fill the questionnaires. Socio-demographic and clinical characteristics of the patients were extracted from the medical charts. Two trained oncology nurses collected the data with daily supervision by the lead investigator. Prior to data collection, the data collectors clearly explained the purpose of the study and what is expected from them. Patients were informed that their responses will not influence the management of their case and an informed consent script which was approved by the ethics committee was read to them by the nurses. Participants were also assured about the confidentiality and anonymity of the information obtained. We omitted personnel identifiers throughout the data collection and, collected data was stored in a lockable cabinet and data entered into SPSS was password protected, access to data was restricted to the research team only, and data were reported in aggregate.

\section{Statistical analysis}

Descriptive statistics were used to report the patients' characteristics. The coefficients of level-specific utility values obtained from a hybrid regression model for the Ethiopian general population were used to compute the utility value. Mean scores were calculated and ANOVA test was employed to examine the significance of mean difference between variables. Stepwise multivariable logistic regression analysis was used to explore the predictors of HRQoL. During bivariate analysis, all variables with $p<0.25$ and clinically significant variables were included for multivariable logistic regression. For the purpose of analysis, we dichotomized the variables into: functional domains and global health status/ QoL score of $<75$ (above 75 indicates "no problem at all") were considered as "affected at any degree" (i.e. poor functioning and global health status/QoL) whereas for symptom domains a score $>25$ (below 25 indicates "no symptom at all") were considered as "affected at any degree". Microsoft Excel was used to calculate the EQ-5D index score but all other statistical analyses were performed using SPSS version 23. All hypotheses involved were two-sided tests; $p<0.05$ was considered statistically significant.

\section{Results}

\section{Sociodemographic and clinical characteristics}

A total of 404 patients participated in the study and their mean age was $52.1 \pm 10.4$ years. More than half $(52 \%)$ of the patients were married and 379 (93.8\%) were managed as outpatients. During the study period, 219 (54.2\%) of the patients were off cancer treatment and 157 (38.9\%) were on radiotherapy. The duration of cancer diagnosis was less than one year in the majority (64.6\%) of patients and 144 (35.60\%) of the patients were diagnosed with the International Federation of Gynecology and Obstetrics (FIGO) stage IV (Table 1).

\section{Health-related quality of life}

The global health status/QoL mean score was $48.3 \pm 23.77$. The EORTC QLQ-C30 multiple and single-item scales were also calculated and the mean score of the functional scales ranged from $40.38 \pm 30.93$ to $79.8 \pm 26.12$, the least being social functioning and the highest cognitive functioning. For the symptom scales, with the exception of diarrhea $(7.43 \pm$ 21.73), the other entire items indicated moderate to high symptoms, of which financial difficulty was the highest $(68.89 \pm 35.42)$. On the other hand, the EORTC QLQ-CX24 domains mean score ranged from $6.12 \pm 19.70$ for sexual activity to $64.56 \pm 29.75$ for sexual/vaginal functioning. On the symptom scales, the least mean score $(12.76 \pm 27.7)$ was on lymphedema and the highest was menopausal symptom (55.77 \pm 35.64$)$ (Table 2).

\section{Mean score differences of EORTC QLQ-C30 and QLQ-CX24 scales with demographic and clinical characteristics}

It was observed that as the stage of cancer increased, the functional and symptom scales of EORTC QLQ-30 as well as the global health status/QoL had a significant mean difference among sociodemographic and clinical characteristics. Fatigue, pain, and loss of appetite resulted significant mean differences across FIGO stages. Patients who had been diagnosed 5 years prior, showed a significantly low mean on fatigue, pain, loss of appetite and financial difficulty scales. Mean differences between body image with demographic and clinical characteristics were significant. Symptom experience and peripheral neuropathy also showed significant mean difference among the different stages of cervical cancer. Details are presented in supplementary file-2.

The EQ-5D utility index and VAS mean score of cervical cancer patients were estimated to be 0.77 and $65.7+20.83$, respectively. The health states reported by patients indicated that most of the cervical cancer patients in Ethiopia had none to moderate problems listed under the EQ-5D descriptive system dimension. About one-third (36.1\%) of patients were able to walk and move without a problem; while the rest reported some to extreme problem with mobility. On the self-care dimension, the majority $(77.5 \%)$ had no problem taking care of themselves and majority (69.3\%) of the patients reported problem with usual activities dimension. Majority of the patients (83.90\%) reported problem with pain/discomfort and approximately two-thirds (60.4\%) of the patients reported slight to extreme problem of anxiety/depression (Fig. 1).

\section{Predictors of health-related quality of life}

The multivariable model of HRQoL outcome revealed that four variables had significant association with the global health status/QoL. The global health status/QoL was significantly associated with physical functioning 
Table 1 Sociodemographic and clinical characteristics of the patients with cervical cancer at Tikur Anbessa Specialized Hospital, Addis Ababa, Ethiopia

\begin{tabular}{|c|c|}
\hline Variables & Number o \\
\hline \multicolumn{2}{|l|}{ Age category } \\
\hline $25-54$ & $230(56.9)$ \\
\hline $55-64$ & $120(29.70$ \\
\hline$>65$ & $54(13.3)$ \\
\hline \multicolumn{2}{|l|}{ Marital status } \\
\hline Single & $5(1.2)$ \\
\hline Married & $210(52)$ \\
\hline Divorced & $69(19.1)$ \\
\hline Widowed & $11(29.0)$ \\
\hline \multicolumn{2}{|l|}{ Religion } \\
\hline Orthodox & $264(65.3)$ \\
\hline Protestant & $78(19.3)$ \\
\hline Muslim & $54(13.4)$ \\
\hline Others & $2(0.5)$ \\
\hline \multicolumn{2}{|l|}{ Educational status } \\
\hline Unable to read and write & $281(69.6)$ \\
\hline Informal education & $28(6.9)$ \\
\hline Primary education & $42(10.4)$ \\
\hline Secondary education & $37(9.2)$ \\
\hline Higher education & $16(4)$ \\
\hline \multicolumn{2}{|l|}{ Occupation status } \\
\hline Government & $23(5.7)$ \\
\hline Private & $10(2.5)$ \\
\hline Merchant & $41(10.1)$ \\
\hline Retired & $9(2.2)$ \\
\hline Farmer & $144(35.6)$ \\
\hline Housewife & $164(40.6)$ \\
\hline Others $^{a}$ & $13(3.2)$ \\
\hline
\end{tabular}

Average monthly household income (Ethiopian Birr)

$\begin{array}{ll}<600 & 177(43.8) \\ >600 & 217(53.7)\end{array}$

FIGO Stage

Unknown

$11(2.70)$

Stage I

$10(2.5)$

Stage II

132 (31.90)

Stage III

108 (26.70)

Stage IV

144 (35.60)

\section{Duration of diagnosis}

$<12$ months

$261(64.6)$

$1-5$ years

$130(32.2)$

$>5$ years

$12(3.0)$
Table 1 Sociodemographic and clinical characteristics of the patients with cervical cancer at Tikur Anbessa Specialized Hospital, Addis Ababa, Ethiopia (Continued)

\begin{tabular}{ll}
\hline Variables & Number of patients (\%) \\
\hline Comorbid conditions & $345(85.4)$ \\
None & $20(5.0)$ \\
Hypertension & $28(6.9)$ \\
HIV/AIDS & $10(2.4)$ \\
Others & \\
Treatment taken & \\
None & $133(32)$ \\
Surgery & $15(3.7)$ \\
Chemotherapy & $16(4.0)$ \\
Radiotherapy & $171(42.3)$ \\
Surgery and Chemotherapy & $10(2.5)$ \\
Chemotherapy and Radiotherapy & $38(9.4)$ \\
Surgery, Chemotherapy and Radiotherapy & $21(5.2)$ \\
\hline
\end{tabular}

Others $^{\mathrm{a}}=$ Housemaids, commercial sex workers and homeless

Others $^{\mathrm{b}}=$ Diabetes Milletus, Peripheral Neuropathy, Anaemia

$(\mathrm{AOR}=4.98,95 \% \mathrm{CI}=2.16-11.49)$, emotional functioning $(\mathrm{AOR}=5.25,95 \% \mathrm{CI}=2.2612 .17)$, pain $(\mathrm{AOR}=5.79$, $95 \% \mathrm{CI}=2.30-14.57)$ and symptom experience $(\mathrm{AOR}=$ $4.58,95 \% \mathrm{CI}=1.95-10.79)($ Table 3$)$.

\section{Discussion}

This is the first study to assess the HRQoL and factors that influence the HRQoL as well as utility among Ethiopian cervical cancer survivors. Overall, pain and anxiety/depression were the most frequently reported symptoms among patients. The different domains of the HRQoL of most patients in this study were generally poor, except diarrhea. Social and sexual functioning domains score of the EORTC QLQ-CX24 were quite lower. Physical functioning, emotional functioning, pain, and symptom experience were significantly associated with patients' overall global health status/QoL. The finding of the present study confirmed that cervical cancer hinders not only the HRQoL but also the holistic management of cervical cancer, which urges the availability of comprehensive treatment strategies to cervical cancer patients.

The general health status/QoL mean score was low, which is consistent with Iranian and Chinese findings $[18,19]$, but lower than Brazilian and Indian studies [20, 21]. The possible reasons could be the cultural belief, distorted perception of survivors regarding their illness, and lower self-esteem [22]. In this study, diarrhea was among the least reported symptoms among cervical cancer survivors, which is similar to the study conducted in India [23]. However, a study done in the United Kingdom showed that diarrhea was the most frequently reported symptom [24]. This might be due to the different 
Table 2 Mean (SD) of EORTC QLQ-C30 and EORTC QLQ-CX24 of patients with cervical cancer at Tikur ASH, Addis Ababa, Ethiopia

\begin{tabular}{|c|c|c|c|}
\hline & EORTC QLQ- C30 & Item Numbers & Mean \pm SD \\
\hline \multirow[t]{17}{*}{ EORTC QLQ-C30 } & Global health status/QoL & 29,30 & $48.3 \pm 23.77$ \\
\hline & \multicolumn{3}{|l|}{ Functional domains } \\
\hline & Physical functioning & $1-5$ & $53.0 \pm 26.05$ \\
\hline & Role functioning & 6,7 & $47.15 \pm 34.05$ \\
\hline & Emotional functioning & $21-24$ & $57.13 \pm 34.50$ \\
\hline & Cognitive functioning & 20,25 & $79.8 \pm 26.12$ \\
\hline & Social functioning & 26,27 & $40.38 \pm 30.93$ \\
\hline & \multicolumn{3}{|l|}{ Symptom domains } \\
\hline & Fatigue & $10,12,18$ & $57.2 \pm 28.1$ \\
\hline & Nausea and vomiting & 14,15 & $21.7 \pm 30.12$ \\
\hline & Pain & 9,19 & $59 \pm 30.07$ \\
\hline & Dyspnea & 8 & $30.8 \pm 32.10$ \\
\hline & Insomnia & 11 & $46.69 \pm 39.25$ \\
\hline & Loss of appetite & 13 & $54.45 \pm 39.28$ \\
\hline & Constipation & 16 & $53.96 \pm 40.78$ \\
\hline & Diarrhea & 17 & $7.43 \pm 21.73$ \\
\hline & Financial difficulty & 28 & $68.89 \pm 35.42$ \\
\hline \multirow[t]{11}{*}{ EORTC QLQ-CX24 } & \multicolumn{3}{|l|}{ Functional domains } \\
\hline & Body image & $45-47$ & $50.27 \pm 38.76$ \\
\hline & Sexual activity & 49 & $6.12 \pm 19.70$ \\
\hline & Sexual enjoyment & 54 & $44.7 \pm 30.37$ \\
\hline & Sexual/Naginal functioning & $50-53$ & $64.56 \pm 29.75$ \\
\hline & \multicolumn{3}{|l|}{ Symptom domains } \\
\hline & Symptom experience & $31-37,38,41-43$ & $42.59 \pm 22.5$ \\
\hline & Lymphedema & 38 & $12.76 \pm 27.7$ \\
\hline & Peripheral neuropathy & 40 & $42.39 \pm 39.27$ \\
\hline & Menopausal symptom & 44 & $55.77 \pm 35.64$ \\
\hline & Sexual worry & 48 & $55.77 \pm 35.64$ \\
\hline
\end{tabular}

treatment protocols used for the management of cancer among the different countries.

The EORTC QLQ-CX24 mean scores demonstrated that younger patients have poor body image and lower sexual/ vaginal functioning as compared to older patients. This finding complements the result of Bae and Park (2016), that poor body image is due to low self-esteem observed among women who have not yet children [25]. Additionally, shame and regret contributed significantly to poorer body image and lower sexual/vaginal functioning in younger age groups [26]. Social and sexual functioning scores were minimal that only $10 \%$ of the patients were sexually active, which is similar to the study conducted elsewhere $[25,26]$.

The finding of the present study confirmed that it is difficult for patients to interact with their partners and face problems to engage in sexual activity due to the disease and treatment burdens. The finding of the present study is consistent with the finding of Froeding et al., (2014), where almost $85 \%$ of the patients lost their sexual interest as well as $50 \%$ of the survivors complain mildly to severe pain during sexual intercourse [27]. Except for diarrhea and lymphedema domains of the EORTC QLQ-CX24, the patients demonstrated low mean scores. This is complementary with another finding, where cervical cancer survivors reported pain in the abdomen, urinary leakage, dyspareunia and menopausal symptoms [28, 29].

In the present study, about $65 \%$ of patients self-reported that their health status is primarily affected by anxiety/depression, which is similar to Scotland's report [30]. The different dimensions of the EQ-5D affected substantially as the disease advanced. The findings indicated that the overall utility score of the patients was 0.77 , which implies that patients favored to live 7.7 years with full health than 10 years with the current health condition. This showed HRQoL becomes an increasingly important concern for both patients and health care providers [25]. 


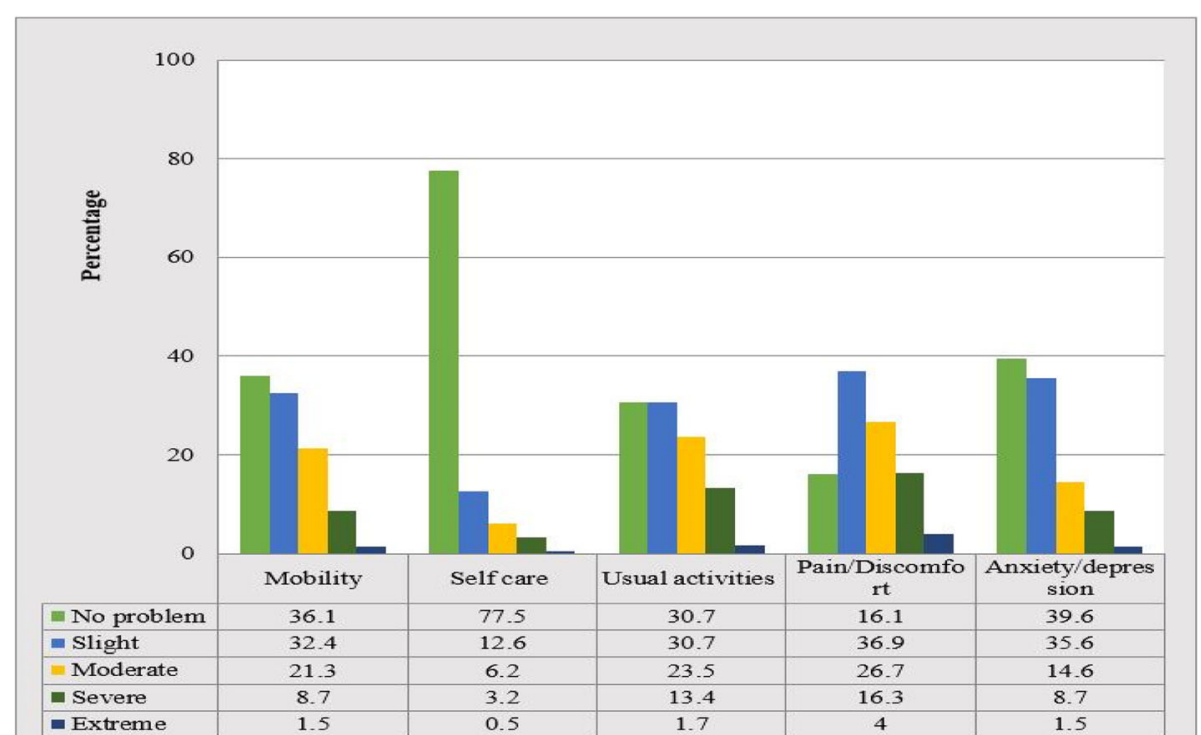

Fig. 1 Descriptive results of EQ-5D dimensions among cervical cancer patients

Physical functioning, emotional functioning, and pain, as well as symptom experience, were associated with patients' global health status/QoL. A study done in Iran found similar predictive factors with the exception of physical functioning [24]. Thus, functioning domains are often a neglected but integral part of the HRQoL of patients that requires evaluation and treatment [31]. In Ethiopia, where women play an important role in the family that affects physical functioning, that might have a large impact on self-satisfaction and HRQoL of patients. Furthermore, inadequate infrastructure and means of transportation in the daily life of a woman from the rural area of Ethiopia becomes an additional burden for them to reach health facility, which affects physical functioning.

The patient's global health status/QoL was highly correlated with the emotional functioning of the cancer survivors, which is in line with another study [32, 33]. The possible reason is that emotional distress, anxiety, depression affects the overall health status of the patients [34]. In complement with the above finding, Herzog and Wright (2007) found that anxiety and emotional distress greatly affected the patients' HRQoL of cervical cancer survivors [24]. The cultural beliefs and illness perception also affect the emotion of the patients as well [31]. Hence, to reduce emotional distress among patients psychological intervention should be commenced.

This study showed that pain and symptom experience were negatively associated with global health status/QoL. Previous studies also found similar findings and emphasized that the degree of pain was directly related to global health status/QoL of patients with cervical cancer patients [25, 34, 35]. Likewise, another study indicated that symptom experiences significantly affect the global health status/QoL of patients [20]. Thus, symptom management should be an important component of patient care for cervical cancer survivors.

In contrary to other studies, the current study did not find a sexual activity as predictive of global health status/QoL of patients [18, 27]. Even though sexual activity is very low, it may not have been predictive due to the values that sexual activity in comparison to the illness. However, studies confirm that the ability to sexual activity had a positive relationship with global health status/ QoL [21, 27]. The recruitment of the small number of sexually active patients might affect the true correlation of the scales; as a result, further researches with larger sample size among sexually active women should be warranted to understand the association.

The study has certain limitations. We used a crosssectional study missing control group and there is no comparison of before and after treatment effects. Further, the study was conducted in a single setting, which might be difficult to generalize for the country. Despite the limitations, the study is the first of its kind to evaluate the HRQoL, factors affecting HRQoL and the utility value of cervical cancer patients in Ethiopia. In addition, we used validated measurement tools and recruited a large sample size. The findings can be used to design effective interventions to improve cervical cancer patient clinical outcomes. It could also help with the economic evaluation of existing and new chemotherapy medications for patients with cervical cancer.

\section{Conclusions}

The finding of the study suggests that the HRQoL patients with cervical cancer in Ethiopian was low with mean global health status/QoL score of $48.3 \pm 23.77$ and 
Table 3 Logistic regression analysis of global health status/QoL of cervical cancer patients with socio-demographic, clinical characteristics, EORTC-QLQ-CX24 and EORTC-QLQ-C 30 subscale variables

\begin{tabular}{|c|c|c|c|c|}
\hline \multirow[t]{2}{*}{ Variables } & \multicolumn{2}{|c|}{ Global health status/QoL, n (\%) } & \multicolumn{2}{|l|}{ Odds Ratio (95\% Cl) } \\
\hline & $\overline{\text { Affected }}$ & Unaffected & $\overline{\mathrm{COR}}$ & AOR \\
\hline \multicolumn{5}{|l|}{ Stage of cancer } \\
\hline Stage 1 & $7(2.1)$ & $3(4.8)$ & $1.33(0.21-8.28)$ & \\
\hline Stage II & $100(29.5)$ & $29(46.0)$ & $1.97(0.53-7.20)$ & \\
\hline Stage III & $91(26.8)$ & $17(27.0)$ & $3.05(0.80-11.60)$ & \\
\hline Stage IV & $134(39.5)$ & $10(15.9)$ & $7.65(1.91-30.63)$ & \\
\hline Unknown & $7(2.1)$ & $4(6.3)$ & 1.00 & \\
\hline \multicolumn{5}{|l|}{ Treatment } \\
\hline None & $119(35)$ & $14(21.9)$ & $3.09(0.867-11.02)$ & \\
\hline Chemotherapy & $15(4.4)$ & $1(1.6)$ & $5.45(0.53-55.80)$ & \\
\hline Radiotherapy & $143(42.1)$ & $28(43.8)$ & $1.85(0.55-6.25)$ & \\
\hline Surgery and Chemotherapy & $5(1.5)$ & $5(7.8)$ & $0.36(0.67-1.19)$ & \\
\hline Chemotherapy and Radiotherapy & $31(9.1)$ & $7(10.9)$ & $1.61(3.94-6.58)$ & \\
\hline Surgery, Chemotherapy and Radiotherapy & $16(4.7)$ & $5(7.8)$ & $1.16(0.25-5.33)$ & \\
\hline Surgery & $11(3.2)$ & $4(6.3)$ & 1.00 & \\
\hline \multicolumn{5}{|l|}{ Time since diagnosis } \\
\hline Less than 12 Month & $227(67)$ & $1(1.0)$ & $5.45(0.53-55.80)$ & \\
\hline $1-5$ years & $108(31.9)$ & $22(34.4)$ & $9.81(2.71-35.48)$ & \\
\hline Above 5 years & $4(1.2)$ & $8(12.5)$ & 1 & \\
\hline \multirow[t]{2}{*}{ Physical functioning } & $297(87.4)$ & $25(39.1)$ & 10.77 (5.94-19.54) & $4.98(2.16-11.49)$ \\
\hline & $43(12.6)$ & $39(60.9)$ & 1.00 & 1.00 \\
\hline \multirow[t]{2}{*}{ Role functioning } & $290(85.3)$ & $21(32.8)$ & $11.8(6.50-21.68)$ & \\
\hline & $50(14.7)$ & $43(67.2)$ & 1.00 & \\
\hline \multirow[t]{2}{*}{ Emotional functioning } & $227(66.8)$ & $15(23.4)$ & $6.52(3.52-12.20)$ & $5.25(2.26-12.17)$ \\
\hline & $113(33.2)$ & $49(76.6)$ & 1.00 & 1.00 \\
\hline \multirow[t]{2}{*}{ Cognitive functioning } & $134(39.4)$ & $10(15.6)$ & $3.51(1.72-7.13)$ & \\
\hline & $206(60.6)$ & $54(84.4)$ & 1.00 & \\
\hline \multirow[t]{2}{*}{ Social functioning } & $316(92.9)$ & $30(46.9)$ & 14.92 (7.84-28.38) & \\
\hline & $24(7.1)$ & $34(53.1)$ & 1.00 & \\
\hline \multirow[t]{2}{*}{ Fatigue } & $313(92.1)$ & $27(42.2)$ & 15.88 (8.43-29.91) & \\
\hline & $27(7.9)$ & $37(57.8)$ & 1.00 & \\
\hline \multirow[t]{2}{*}{ Nausea and vomiting } & $132(38.8)$ & $6(9.4)$ & $6.13(2.57-14.61)$ & \\
\hline & $208(61.2)$ & $58(90.6)$ & 1.00 & \\
\hline \multirow[t]{2}{*}{ Pain } & $318(93.5)$ & $25(39.1)$ & $22.54(11.62-43.73)$ & $5.79(2.30-14.57)$ \\
\hline & $22(6.5)$ & $39(60.9)$ & 1.00 & 1.00 \\
\hline \multirow[t]{2}{*}{ Dyspnea } & $212(62.4)$ & $14(21.9)$ & $5.91(3.14-11.12)$ & \\
\hline & $128(37.6)$ & $50(78.1)$ & 1.00 & \\
\hline \multirow[t]{2}{*}{ Insomnia } & $250(73.5)$ & $25(39.1)$ & $4.33(2.48-7.5)$ & \\
\hline & $90(26.5)$ & 39 (60.9) & 1.00 & \\
\hline \multirow[t]{2}{*}{ Loss of appetite } & $273(80.3)$ & $26(40.6)$ & 5.95 (3.38-10.48) & \\
\hline & $67(19.7)$ & $38(59.4)$ & 1.00 & \\
\hline \multirow[t]{2}{*}{ Constipation } & $256(75.3)$ & 25 (39.1) & $4.75(2.71-8.31)$ & \\
\hline & $84(24.7)$ & 39 (60.9) & 1.00 & \\
\hline
\end{tabular}


Table 3 Logistic regression analysis of global health status/QoL of cervical cancer patients with socio-demographic, clinical characteristics, EORTC-QLQ-CX24 and EORTC-QLQ-C 30 subscale variables (Continued)

\begin{tabular}{|c|c|c|c|c|}
\hline \multirow[t]{2}{*}{ Variables } & \multicolumn{2}{|c|}{ Global health status/QoL, n (\%) } & \multicolumn{2}{|l|}{ Odds Ratio $(95 \% \mathrm{Cl})$} \\
\hline & Affected & Unaffected & COR & AOR \\
\hline \multirow[t]{2}{*}{ Diarrhea } & $47(13.8)$ & $2(3.1)$ & $4.97(1.17-21.01)$ & \\
\hline & $293(86.2)$ & $62(96.9)$ & 1 & \\
\hline \multirow[t]{2}{*}{ Financial difficulty } & $306(90)$ & $41(64.1)$ & $5.04(2.71-9.39)$ & \\
\hline & $34(10.0)$ & $23(35.9)$ & 1.00 & \\
\hline \multirow[t]{2}{*}{ Body image } & $242(71.2)$ & $22(34.4)$ & $4.71(2.67-8.30)$ & \\
\hline & $98(28.8)$ & $42(65.6)$ & 1.00 & \\
\hline \multirow[t]{2}{*}{ Sexual activity } & $334(98.5)$ & $61(95.3)$ & $3.28(0.76-14.10)$ & \\
\hline & $5(1.5)$ & $3(4.7)$ & 1.00 & \\
\hline \multirow[t]{2}{*}{ Sexual functioning } & $16(57.1)$ & $4(30.8)$ & $3.00(0.74-12.11)$ & \\
\hline & $12(42)$. & $9(69.2 \%)$ & 1.00 & \\
\hline \multirow[t]{2}{*}{ Symptom experience } & $279(85.8)$ & $16(27.6)$ & $15.92(8.27-30.64)$ & $4.58(1.95-10.79)$ \\
\hline & $46(14.2)$ & $42(72.4)$ & 1.00 & 1.00 \\
\hline \multirow[t]{2}{*}{ Peripheral neuropathy } & $222(65.3)$ & $25(39.1)$ & $2.93(1.69-5.08)$ & \\
\hline & $118(34.7)$ & $39(60.9)$ & 1.00 & \\
\hline \multirow[t]{2}{*}{ Menopausal symptoms } & $285(83.8)$ & $34(53.1)$ & $4.57(2.58-8.08)$ & \\
\hline & $55(16.2)$ & $30(46.9)$ & 1.00 & \\
\hline
\end{tabular}

EQ-5D index of 0.77. Physical functioning, emotional functioning, pain, and symptom experience significantly affects the global health status/QoL. Hence, symptom management strategies in addressing the functioning and symptoms of patients should be warranted. Furthermore, in order to recognize the disease at an early stage, screening of cervical cancer is recommended.

\section{Supplementary information}

Supplementary information accompanies this paper at https://doi.org/10. 1186/s12955-020-01319-x.

Additional file 1: S1. EORTC QLQ-C30 (version 3) and EORTC QLQ-

CX24.

Additional file 2: S2. Mean differences of EORTC QLQ-C30 functional scale with demographic and clinical characteristics of patients at Tikur Anbessa Specialized Hospital, Addis Ababa, Ethiopia.

\section{Abbreviations}

ECOG-PS: European Cooperative Oncology Group Performance Status; EORTC QLQ-CX24: European Organization for Research and Treatment of Cancer Quality of life Questionnaires cervical cancer-specific module; EORTC QLQC30: European Organization for Research and Treatment of Cancer Quality of life Questionnaires version 30; FIGO: International Federation of Gynaecology and Obstetrics; HRQoL: Health-Related Quality of Life; TASH: Tikur Anbessa Specialized Hospital

\section{Acknowledgments}

The authors would like to thank Addis Ababa University for providing financial support for carrying out this study. We would like to extend our sincere thanks to all research participants as well as pharmacists, nurses, and physicians working in the hospital.

\section{Authors' contributions}

LTA and GBG conceived the research idea, did translation and transcultural adaptation of the EORTC-QLQ-CX24; LTA, GBG, GTG and TGF performed data analysis and interpretation; LTA write original draft of the manuscript; LTA, GTG, GBG and TGF: reviewed and edited the manuscript. All authors critically evaluated the final manuscript for important intellectual content and approved the final version of the manuscript.

\section{Authors' information}

LTA is a pharmacist who graduated with a MSC in Pharmacoepidemiology and Social Pharmacy from the School of Pharmacy, College of Health Sciences, Addis Ababa University. BS is an associate professor \& faculty lead Health Technology Assessment program at the University of Toronto, Canada Research Chair in Economics of Infectious Diseases, Scientist \& Director at the Toronto Health Economics and Technology Assessment (THETA) collaborative and an adjust scientist at Public Health Ontario and ICES (formerly known as Institute for Clinical Evaluative Sciences) in Canada. TGF is a professor of Pharmacoepidemiology at the School of Pharmacy, College of Health Sciences, Addis Ababa University. GTG is a lecturer at the School of Pharmacy, College of Health Sciences, Addis Ababa University. GBG is an assistant professor at the School of Pharmacy, College of Health Sciences, Addis Ababa University, Ethiopia.

\section{Funding}

Addis Ababa University funded this study for partial fulfillment of a Master's degree in Pharmacoepidemiology and Social Pharmacy.

\section{Availability of data and materials}

The dataset which the study is based on is publicly not available due to required data protection but is available upon reasonable request with a signature of a data privacy form. To request the data, the reader may contact the authors through email.

\section{Ethics approval and consent to participate}

Ethical approval was obtained from the Ethics Review Board of the School of Pharmacy, Addis Ababa University (Ref. No.: ERB/SOP/07/10/2018) and permission was received from the study hospital. Written informed consent was obtained from patients. 


\section{Consent for publication}

Not applicable.

\section{Competing interests}

The authors declare that they have no competing interests.

\section{Author details}

'Social and Administrative Pharmacy Unit, School of Pharmacy, College of Health Sciences, Addis Ababa University, Zambia Street, P.O. Box: 1176, Addis Ababa, Ethiopia. ${ }^{2}$ Institute of Health Policy, Management and Evaluation, University of Toronto, Toronto, Ontario, Canada. ${ }^{3}$ Toronto Health Economics and Technology Assessment (THETA) Collaborative, University Health Network, Toronto, Ontario, Canada. ${ }^{4}$ ICES, Toronto, Ontario, Canada. ${ }^{5}$ Public Health Ontario, Toronto, Ontario, Canada. ${ }^{6}$ Department of Pharmacology and Clinical Pharmacy, School of Pharmacy, College of Health Sciences, Addis Ababa University, Addis Ababa, Ethiopia.

\section{Received: 2 December 2019 Accepted: 9 March 2020}

\section{Published online: 16 March 2020}

\section{References}

1. Bray F, Ferlay J, Soerjomataram I, Siegel RL, Torre LA, Jemal A. Global cancer statistics 2018: GLOBOCAN estimates of incidence and mortality worldwide for 36 cancers in 185 countries. CA Cancer J Clin. 2018:68(6):394-424.

2. World Health Organization (WHO). WHO leads the way towards the elimination of cervical cancer as a public health concern. Geneva: WHO; 2019. Available at: https://www.who.int/reproductivehealth/cervical-cancerpublic-health-concern/en/ Accessed on August 12, 2019.

3. Bruni L, Albero G, Serrano B, Mena M, Gómez D, Muñoz J, Bosch FX, de Sanjosé S. ICO/IARC Information Centre on HPV and Cancer (HPV Information Centre). Human Papillomavirus and Related Diseases in the World. Summary Report 17 June 2019. availabe at: https://hpvcentre.net/ statistics/reports/XFX.pdf. Accessed on August 12, 2019.

4. Hailemariam T, Yohannes B, Aschenaki H, Mamaye E, Orkaido G, Seta M. Prevalence of cervical Cancer and associated risk factors among women attending cervical Cancer screening and diagnosis Center at Yirgalem General Hospital, Southern Ethiopia. J Cancer Sci Ther. 2017:9(11):730-5.

5. Federal Ministry of Health E. National Cancer Control and Implementation Plan. 2019;Availablefrom: https://www.iccpportal.org/sites/default/files/plans/ NCCP\%25Ethiopia\%25final\%2520261015.pdf. Accessed on August 12, 2019

6. Catarino R, Petignat P, Dongui G, Vassilakos P. Cervical cancer screening in developing countries at a crossroad: emerging technologies and policy choices screening for cervical cancer screening in developing countries. World J Clin Oncol. 2015:6(6):281-90.

7. Fayers P, Machin D. Quality of Life: The assessment, analysis and interpretation of patient-reported outcomes. 2nd ed. Chichester: John Wiley \& Sons; 2007. p. 544

8. Saleha SB, Shakeel A, Shumaila E, Shazia R, Rashid R, Ibrahim M. An assessment of quality of life in breast cancer patients using EORTC QLQ C30/+BR23 questionnaire. Iran J Cancer Prev. 2010;3(2):98-104.

9. Basch E, Snyder C, McNiff K, Brown R, Maddux S, Smith M. Lou, et al. patient-reported outcome performance measures in oncology. J Oncol Pract. 2014;10(3):209-11.

10. Endarti D, Riewpaiboon A, Thavorncharoensap M, Praditsitthikorn N, Hutubessy R, Kristina SA. Evaluation of health-related quality of life among patients with cervical cancer in Indonesia. Asian Pacific J Cancer Prev. 2015; 16(8):3345-50.

11. Teckle P, Peacock S, McTaggart-Cowan H, Hoek K, Chia S, et al. The ability of cancer specific and generic preference-based instruments to discriminate across clinical and self reported measures of cancer severities. Health Qual Life Outcomes. 2011;9:106.

12. Aaronson NK, Ahmedzai S, Bergman B, Bullinger M, Cull A, Duez NJ, et al. The European Organization for Research and Treatment of Cancer QLQ-C30: a quality-of-life instrument for use in international clinical trials in oncology. J Nat Cancer Inst. 1993;85(5):365-76.

13. Greimel ER, Vlasic KK, Waldenstrom AC, Duric VM, Jensen PT, Singer $S$, et al. The European Organization for Research and Treatment of Cancer (EORTC) quality-of-life questionnaire cervical cancer module: EORTC QLQ-CX24. Cancer. 2006;107(8):1812-22.

14. Longworth L, Yang Y, Young T, Mulhern B, Hernández Alava M, Mukuria C et al. Use of generic and condition-specific measures of health-related quality of life in NICE decision-making: a systematic review, statistical modelling and survey. Health Technol Assess 2014:18(9).

15. Rabin R, Fd C. EQ-SD: a measure of health status from the EuroQol group. Ann Med. 2001:33:337-43.

16. Preedy VR, Watson RR. In: Watson RR, editor. Handbook of disease burdens and quality of life measures. New York: Springer; 2010. p. 87-99.

17. Feng Y, Parkin D, Devlin NJ. Assessing the performance of the EQ-VAS in the NHS PROMs programme. Qual Life Res. 2014;23(3):977-89.

18. Torkzahrani S, Rastegari L, Khodakarami N, Akbarzadeh-Baghian A, Alizadeh K. Quality of life and its related factors among Iranian cervical Cancer survivors. Iran Red Crescent Med J. 2013:15(4):320-3.

19. Huang HY, Tsai WC, Chou WY, Hung YC, Liu LC, Huang KF, et al. Quality of life of breast and cervical cancer survivors. BMC Womens Health. 2017;17(30):1-12.

20. Araújo Correia R, Prazeres Marques LJ, Laurentino dos Santos S, Vieira do Bonfim C. Quality of life and sexual function after cervical cancer: a crosssectional study. Brazilian J Nurs. 2016;15:1-10.

21. Prasongvej $P$, Nanthakomon $T$, Jaisin $K$, Chanthasenanont $A$, Lertvutivivat $S$, Tanprasertkul C, et al. Quality of life in cervical Cancer survivors and healthy women: Thai urban population study. Asian Pac J Cancer Prev. 2017;18(2):385-9.

22. Khalil J, Bellefqih S, Sahli N, Afif M, Elkacemi H, Elmajjaoui S, et al. Impact of cervical cancer on quality of life: beyond the short term (results from a single institution). Gynecol Oncol Res Pract. 2015;2(7):2-6.

23. Bjelic-Radisic V, Jensen PT, Vlasic KK, Waldenstrom AC, Singer S, Chie W, Nordin A, Greimel E. Quality of life characteristics inpatients with cervica cancer. Eur J Cancer. 2012;48(16):3009-18.

24. McKenzie L, Van Der Pol M. Mapping the EORTC QLQ C-30 onto the EQ-5D instrument: the potential to estimate QALYs without generic preference data. Value Heal. 2009;12(1):167-71.

25. Lee Y, Lim MC, Kim SI, Joo J, Lee DO, Park SY. Comparison of quality of life and sexuality between cervical cancer survivors and healthy women. Cancer Res Treat. 2016:48(4):1321-9.

26. Bae H, Park H. Sexual function, depression, and quality of life in patients with cervical cancer. Support Care Cancer. 2016:24(3):1277-83.

27. Herzog TJ, Wright JD. The impact of cervical cancer on quality of life the components and means for management. Gynecol Onco. 2007;107(3):572-7.

28. Froeding LP, Ottosen C, Rung-Hansen H, Svane D, Mosgaard BJ, Jensen PT. Sexual functioning and vaginal changes after radical vaginal trachelectomy in early stage cervical cancer patients: a longitudinal study. J Sex Med. 2014;11:595-604.

29. Korfage IJ, Essink-Bot ML, Mols F, van de Poll-Franse L, Kruitwagen R, van Ballegooijen M. Health-related quality of life in cervical Cancer survivors: a population-based survey. Int J Radiat Oncol Biol Phys. 2009;73:1501-9.

30. Kumar S, Rana ML, Verma K, Singh N, Sharma AK, Maria AK, et al. Predi Qtcx: post treatment health related quality of life prediction model for cervical cancer patients. PLoS One. 2014;9(2):e89851.

31. Xie Y, Zhao FH, Lu SH, Huang H, Pan XF, Yang CX, et al. Assessment of quality of life for the patients with cervical cancer at different clinical stages. Chin J Cancer. 2013;32(5):275-82.

32. Li Q, Lin $Y, X u Y, Z$ Zhou $H$. The impact of depression and anxiety on quality of life in Chinese cancer patient-family caregiver dyads, a cross-sectional study. Health Qual Life Outcomes. 2018;16(1):2-15.

33. Shin JY, Lim JW, Shin DW, Kim SY, Yang HK, Cho J, et al. Underestimated caregiver burden by cancer patients and its association with quality of life, depression and anxiety among caregivers. Eur J Cancer Care (Engl). 2018; 27(2):e12814.

34. Park B, Kim SY, Shin JY, Sanson-Fisher RW, Shin DW, Cho J, et al. Prevalence and predictors of anxiety and depression among family caregivers of cancer patients: a nationwide survey of patient-family caregiver dyads in Korea. Support Care Cancer. 2013;21:2799-807.

35. Tadele N. Evaluation of quality of life of adult cancer patients attending Tikur Anbessa specialized referral hospital, Addis Ababa Ethiopia. Ethiop J Health Sci. 2015:25(1):3-62

\section{Publisher's Note}

Springer Nature remains neutral with regard to jurisdictional claims in published maps and institutional affiliations. 